\title{
Influence of Processing Conditions on the Thermal Stability and Mechanical Properties of PP/Silica-Lignin Composites
}

\author{
Lukasz Klapiszewski, ${ }^{1}$ Karol Bula, ${ }^{2}$ Marta Sobczak, ${ }^{2}$ and Teofil Jesionowski ${ }^{1}$ \\ ${ }^{1}$ Institute of Chemical Technology and Engineering, Faculty of Chemical Technology, Poznan University of Technology, \\ Berdychowo 4, 60965 Poznan, Poland \\ ${ }^{2}$ Institute of Materials Technology, Faculty of Mechanical Engineering and Management, Poznan University of Technology, \\ Jana Pawla II 24, 60965 Poznan, Poland \\ Correspondence should be addressed to Teofil Jesionowski; teofil.jesionowski@put.poznan.pl
}

Received 30 September 2015; Revised 12 January 2016; Accepted 19 January 2016

Academic Editor: Antje Potthast

Copyright (C) 2016 Łukasz Klapiszewski et al. This is an open access article distributed under the Creative Commons Attribution License, which permits unrestricted use, distribution, and reproduction in any medium, provided the original work is properly cited.

\begin{abstract}
Functional silica-lignin dual fillers were obtained via mechanical grinding of the components (Syloid 244 silica and kraft lignin). Of particular importance here is the fact that lignin is a natural polymer and particularly that it is a waste by-product of paper production, whose recycling is highly desirable. The product underwent comprehensive dispersive-morphological and thermal analysis. $\mathrm{SiO}_{2}$-lignin hybrid fillers were also used in polypropylene-based composites, extruded via corotating a twin screw machine with different screw speeds. The thermogravimetric data obtained for the extrudates confirmed that the application of the lignin into PP produces a significant char residue. Addition of silica to lignin via this new hybrid formulation has a positive effect on the thermal stability of $\mathrm{PP} /$ silica-lignin composites, which can be seen even when observing the temperature for the maximum rate of weight reduction. Tensile test results show that the addition of silica by means of dual filler incorporation improves the mechanical parameters in comparison with pure PP and PP/lignin composite.
\end{abstract}

\section{Introduction}

The continued growth of research in advanced materials engineering and polymer technology yields the possibility of carrying out interdisciplinary work related to obtaining innovative and functional hybrid materials. Currently, it is important for economic and environmental reasons to use natural polymers as organic precursors that are derived from broadly defined biomasses or other sources. Particularly, noteworthy are the systems with silica, which represents a popular, relatively inexpensive inorganic filler or support, and biopolymers, for example, lignin [1-3] and its derivatives, including lignosulfonates $[4,5]$.

Reports in the literature indicate the possible use of lignocellulosic materials, including pure lignin, as fillers in a wide group of polymers. These include both highly polar (poly(ethylene terephthalate), PET, poly(ethylene oxide), PEO) $[6,7]$ and hydrophobic (polypropylene, PP) [8-10] polymer matrices. Studies have also been carried out with polylactide (PLA) [11-14] and poly(vinyl chloride) $[15,16]$. The latter showed better compatibility of PVC with lignin for unplasticized material than for the plasticized form.

The use of lignin as a polymer filler depends largely on its thermal stability. Thermal decomposition of the biopolymer depends mainly on the type of lignin, the temperature of the process, and the heating rate [17]. According to the available sources, the thermal decomposition of lignin takes place in the temperature range between 200 and $500^{\circ} \mathrm{C}$ [17-20].

Below $150^{\circ} \mathrm{C}$ the physically bound water evaporates, and then further degradation of the biopolymer chain occurs, which takes place in two stages [18]. The first starts at relatively low temperatures, approximately $200-275^{\circ} \mathrm{C}$, and is connected to the thermal decomposition of lignin, involving the formation of new bonds as a consequence of cross-linking reactions. The highest stage of decomposition of lignin takes place at a temperature of $\sim 400^{\circ} \mathrm{C}$, where it creates aromatic hydrocarbons, phenolics, and compounds containing phenolic groups [17]. The thermal stability of lignin is therefore 
relatively high at plastic processing temperatures, so it can be used as a material for increasing the stability of the product [19]. The mass loss of lignosulfonate (lignin derivative) was significant and reached $60 \%$ relative to the initial mass of the sample [4]. The thermogravimetric curve recorded for lignosulfonate exhibits two characteristic stages. The first, below $200^{\circ} \mathrm{C}$, results from endothermic water desorption from the sample. The second, more severe mass loss ( $40 \%$ ), starting at a temperature of about $200^{\circ} \mathrm{C}$, reflects the gradual degradation and consequent fragmentation of the compound. The results are in agreement with data given by Brebu et al. [21] and Lemes et al. [22].

Other frequently used biopolymers that also widely occur, often as waste, are chitin, chitosan, and cellulose. Chitin is a biopolymer with relatively high thermal stability, even at $380^{\circ} \mathrm{C}$ [23-25]. However, the thermal degradation of chitin is dependent on several factors including acetylation, degree of crystallinity, and size of crystallites, and it is also strongly related to the origin of the material. Deacetylation decreases the thermal stability of chitin, and thus chitin has higher thermal stability than chitosan. Nam et al. [25] proved that thermal decomposition of chitin nanofibers follows a singlestep degradation process, although chitosan nanofibers with a deacetylation degree (DD) greater than 50\% exhibited a two-step mechanism. This thermal property is the driving force for developing new chitin-based materials and chitin processing routes at high temperatures using the principles of hydrothermal synthesis and extreme biomimetics [26].

In turn, literature data indicate that the thermal stability curve of chitosan presents two significant decreases in weight. The first, at $\sim 90^{\circ} \mathrm{C}$, associated with a weight loss of $\sim 6 \%$ of the sample, is due to the evaporation of physically bound water on the surface $[27,28]$. The second, starting at approximately $245^{\circ} \mathrm{C}$ and ending at approximately $580^{\circ} \mathrm{C}$, involves $\sim 80 \%$ decrease in the mass of the sample. This decrease is related to the thermal degradation of the polymer chain of chitosan. The question of thermal stability is crucial when planning futureoriented processing of this material in industry [29].

A number of studies have also been carried out with cellulose [30]. TGA curves show three stages of degradation of cellulose. The first of these, at $200-300^{\circ} \mathrm{C}$, is associated with a partial disintegration of biopolymer and water loss (a weight loss of about $4 \%$ ). In a further step, at a temperature of $300-360^{\circ} \mathrm{C}$, the sample undergoes a weight loss of about $55 \%[31,32]$. The last stage, with a sample weight loss of about $29 \%$, occurs gradually at $360-440^{\circ} \mathrm{C}$. The second stage which is of rapid loss plays a key role in defining the stability and fire retardancy of cellulose [31].

Many studies have been focused on lignin precursors as a factor in char formation during polymer burning, together with the addition of inorganic filler, but no one has combined these two materials as a single hybrid (duo) filler. Therefore, the objective of this study is to determine the influence of the presence of silica and lignin in a dual phase-like filler on the thermal degradation of polypropylene during melt-compounding. Additionally, the impact of the filler on processing degradation, as a function of extrusion parameters (screw speed), will be discussed. The effect of processing degradation on the composite's performance will be evaluated based on rheology (MFR), mechanical properties, and thermogravimetric measurements.

\section{Materials and Methods}

2.1. Materials. The organic component kraft lignin was supplied by Sigma-Aldrich, USA. The properties of the lignin are described in detail in our previously published papers $[33,34]$. For the production of silica-lignin hybrid fillers, the commercial silica Syloid 244 from W.R. Grace \& Co., USA, was used. The polymer matrix used was isotactic polypropylene (iPP) (Basell Orlen Polyolefins Sp. z o.o., Moplen HP 500 N, Poland).

2.2. Preparation of Hybrid Materials Based on Silica and Lignin. Silica-lignin fillers were produced via a grinding and mechanical-alloying-like method. To combine the $\mathrm{SiO}_{2}$ and lignin, a mechanical process was used whereby the initial powders (kraft lignin and silica Syloid 244) were ground and simultaneously mixed using a Pulverisette 6 Classic Line planetary ball mill (Fritsch, Germany). This process was described in detail in our previously published work [33].

Three types of hybrid fillers were prepared, differing by their lignin content. $\mathrm{SiO}_{2}$-lignin hybrid fillers were produced with the ratio of precursors equal to $5: 1,2: 1$, and $1: 1$.

\subsection{Physicochemical Characteristics of Fillers}

2.3.1. Dispersive-Morphological Properties. Dispersive characteristics of pure precursors and silica-lignin hybrid fillers were determined with the use of a Zetasizer Nano ZS and Mastersizer 2000, both made by Malvern Instruments Ltd. (UK), employing the methods of dynamic light scattering (DLS) and laser diffraction, respectively. Measurements of particle size were repeated at least three times for each sample.

Information on grain morphology, particle shape, character of agglomerations, and dispersion was obtained from scanning electron microscope (SEM) images (Zeiss EVO40, Germany). Prior to the testing, the samples were coated with $\mathrm{Au}$ for a time of 5 seconds using a Balzers PV205P coater.

2.3.2. Thermogravimetric Analysis. Thermogravimetric analysis was performed using a Jupiter STA449 F3 (Netzsch, Germany). Samples weighing approximately $10 \mathrm{mg}$ were placed in an $\mathrm{Al}_{2} \mathrm{O}_{3}$ crucible and heated at a rate of $10^{\circ} \mathrm{C} / \mathrm{min}$ from 30 to $1000^{\circ} \mathrm{C}$ in a nitrogen atmosphere, at a flow rate of $40 \mathrm{~cm}^{3} / \mathrm{min}$.

2.4. Preparation of PP/Silica-Lignin Composites via Extrusion. Isotactic polypropylene (iPP) was supplied by Basell Orlen Polyolefins Sp. z o.o. (Moplen HP $500 \mathrm{~N}$ ) and had a melt flow rate (MFR) of $12 \mathrm{~g} / 10 \mathrm{~min}$ at $230^{\circ} \mathrm{C}$. The processing of $\mathrm{PP} /$ silica-lignin composites was conducted into two steps. First, each of the three types of silica-lignin hybrid fillers (differing in lignin content) was mixed separately with PP in a molten state using a twin screw extruder. All samples and their composition are described in Table 1.

Next, the pelletized composites were shaped into dog bone samples using an injection molding technique. At the beginning of the extrusion process, the main components 
TABLE 1: Formulations of PP-based composites.

\begin{tabular}{lccc}
\hline \multirow{2}{*}{ Sample notation } & \multicolumn{3}{c}{ Composition (wt.\%) } \\
& Polypropylene & Kraft lignin & Silica Syloid 244 \\
\hline $\mathrm{PP}$ & 100.0 & - & - \\
$\mathrm{PP} /$ lignin & 90.0 & 10.0 & - \\
$\mathrm{PP} / \mathrm{SiO}_{2}$-lignin & 90.0 & 5.0 & 5.0 \\
$(1: 1, \mathrm{w} / \mathrm{w})$ & & 3.3 & 6.6 \\
$\begin{array}{l}\mathrm{PP} / \mathrm{SiO}_{2} \text {-lignin } \\
(2: 1, \mathrm{w} / \mathrm{w})\end{array}$ & 90.0 & & \\
$\begin{array}{l}\mathrm{PP} / \mathrm{SiO}_{2} \text {-lignin } \\
(5: 1, \mathrm{w} / \mathrm{w})\end{array}$ & 90.0 & 1.7 & 8.3 \\
\hline
\end{tabular}

were preweighed and mixed in granular (PP) and powder states (silica-lignin hybrid fillers) in a rotating container. In the next operation, the prepared batches were dried in an air-circulating oven at $80^{\circ} \mathrm{C}$ for $12 \mathrm{~h}$. After drying, all mixed compounds were fed into a corotating twin screw extruder (Zamak 16/40 EHD) with a barrel temperature of $155-185^{\circ} \mathrm{C}$. The plasticizing unit has screws with a diameter of $16 \mathrm{~mm}$ and an $L / D$ ratio of 40 and is equipped with four kneading disc blocks and mixing elements. The screw configuration and detailed information about screw sections and the design of the mixing elements are supplied in Figure 1.

During extrusion, all composites as well as virgin polypropylene were extruded under four different screw rotation speeds: 100, 200,300, and $400 \mathrm{rpm}$. The extrudates were cooled under dry conditions in atmospheric air to prevent any moisture absorption. Next, the extrudates were reground using a laboratory grinder (SC-1411 Shini), operating at a low rotor speed of $30 \mathrm{rpm}$ to prevent overheating and further organic phase decomposition via high shear stress concentration.

Finally, the neat PP and the compounds were injectionmolded into dumbbell-shaped specimens using an ENGEL 80/25 HLS injection molding machine, at a mold temperature of $30^{\circ} \mathrm{C}$. The barrel temperature was set as $175^{\circ} \mathrm{C}, 180^{\circ} \mathrm{C}, 185^{\circ} \mathrm{C}$, and $190^{\circ} \mathrm{C}$ (nozzle). The injection speed was low, at $50 \mathrm{~mm} / \mathrm{s}$. The injection speed used was sufficient for cavity filing and probably did not cause any overheating of the polymer phase and degradation of macromolecules by extended shear forces.

For tensile test bar preparation, a cavity mould with a thickness of $3 \mathrm{~mm}$ was used. The main dimensions of the utilized specimens were $115 \mathrm{~mm}$ total length, $25 \mathrm{~mm}$ gauge length, and $6 \mathrm{~mm}$ width.

2.5. Polymer Composite Testing. The mass melt flow rate of all extrudates was evaluated using the melt indexer Dynisco Polymer, TEST 4004 , under $2.16 \mathrm{~kg}$ and a temperature of $230^{\circ} \mathrm{C}$.

For TGA analysis, only the samples obtained with screw speeds of $100 \mathrm{rpm}$ and $400 \mathrm{rpm}$ were selected. Extrudates were directly tested by thermogravimetric analysis using a TG 209 FI LIBRA analyzer (Netzsch, Germany) in a nitrogen atmosphere. The heating rate was $10^{\circ} \mathrm{C} / \mathrm{min}$ and the nitrogen flow rate was $60 \mathrm{~cm}^{3} / \mathrm{min}$. The temperature ranged from 30 to $700^{\circ} \mathrm{C}$.

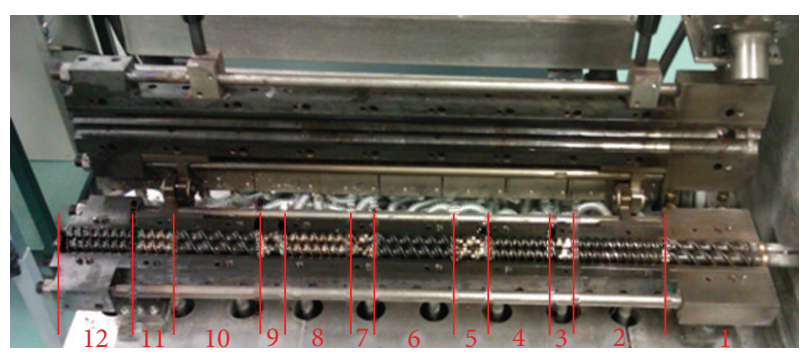

FIGURE 1: View of the opened plastisizing unit with screws working in a corotating mode. Zone 1: feed area ( $32 \mathrm{~mm}$ screw stroke), zones $2,4,6,8$, and 11: transporting sections, zones 3, 5, 7, and 9: kneading and mixing elements, zone 10: degassing unit, and zone 12: metering section (16 mm screw stroke). Compression factor $=2$.

Tensile properties (yield strength, tensile strength, elongation, and modulus) were determined using an Instron 4481 universal testing machine at a crosshead speed of $50 \mathrm{~mm} / \mathrm{min}$, at room temperature, in accordance with ISO $527-1,2$. The samples were not conditioned prior to testing, because for polyolefins the influence of moisture on mechanical properties is negligible.

\section{Results and Discussion}

3.1. Dispersive-Morphological Properties and Thermal Stability of Silica-Lignin Hybrid Fillers. Syloid 244 reveals the presence of primary particles with diameters close to $100 \mathrm{~nm}$, which show a tendency to form aggregates $(<1 \mu \mathrm{m})$ and agglomerates $(>1 \mu \mathrm{m})$. Silica exhibits different dispersivemorphological properties (see Table 2 and Figure 2(a)).

As follows from the data presented in Table 2, with the increasing content of lignin in the hybrid filler, the number of larger particles increases. This tendency is evident for the hybrid fillers based on Syloid 244 silica. The parameters from the Mastersizer 2000 describing the percentage contribution of particles of certain diameters show an increase. It should be noted that the commercial kraft lignin used in the study contains particles of sizes representing a wide range, which indicates the possibility of formation of large agglomerate structures. The presence of primary particles and secondary agglomerates is also confirmed by SEM images.

Figures 2(a) and 2(b) present the SEM images of silica and lignin, respectively, while Figures 2(c)-2(e) show images of silica-lignin hybrids obtained with the use of different weight ratios of biopolymer to silica.

Thermal stability measurements for the silica, lignin, and inorganic-organic materials were also performed. Figure 3 shows the TGA curves obtained for the precursors and the resulting silica-lignin dual fillers. Syloid 244 silica shows high thermal stability: a mass loss was observed at $100^{\circ} \mathrm{C}$ associated with the loss of water physically bound with the precursor. In the case of lignin, the thermogravimetric curve shows a clearly larger mass loss in comparison with silica. The TGA curve recorded for lignin indicates a significant mass loss of about $65 \%$ relative to the initial mass of the sample. The 
TABLE 2: Dispersive characteristic of pure precursors (silica and lignin) and silica-lignin hybrid fillers.

\begin{tabular}{|c|c|c|c|c|}
\hline \multirow{3}{*}{ Sample } & \multicolumn{4}{|c|}{ Dispersive properties } \\
\hline & \multirow{2}{*}{ Particle size distribution from Zetasizer Nano ZS (nm) } & \multicolumn{3}{|c|}{ Particle diameter from Mastersizer $2000(\mu \mathrm{m})$} \\
\hline & & $d(0.1)$ & $d(0.5)$ & $d(0.9)$ \\
\hline Syloid 244 + kraft lignin $(1: 1)$ & $106-295 ; 1990-5560$ & 2.8 & 9.2 & 20.0 \\
\hline Syloid $244+$ kraft lignin $(2: 1)$ & $91-220 ; 1990-4800$ & 2.7 & 9.0 & 19.9 \\
\hline Syloid $244+$ kraft lignin $(5: 1)$ & $79-122 ; 1720-4150$ & 2.8 & 8.7 & 19.5 \\
\hline Syloid 244 & $39-295 ; 1720-2670$ & 2.0 & 7.2 & 18.1 \\
\hline Kraft lignin & $1990-5560$ & 5.0 & 12.5 & 38.6 \\
\hline
\end{tabular}

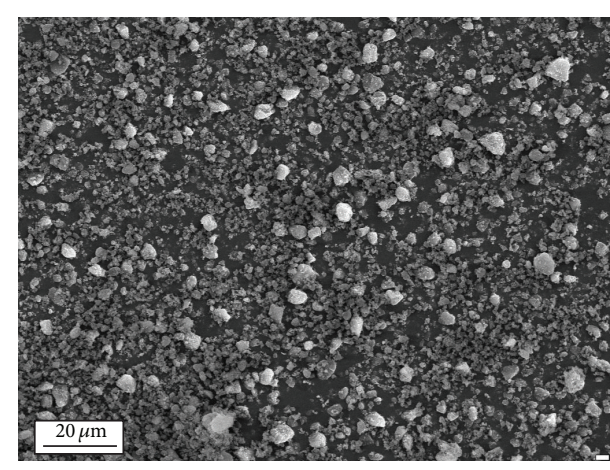

(a)

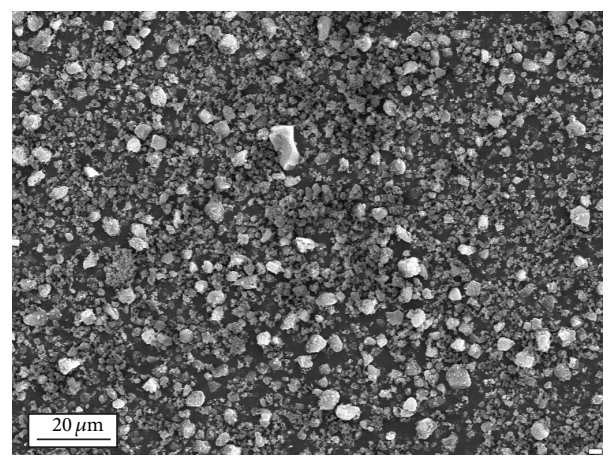

(c)

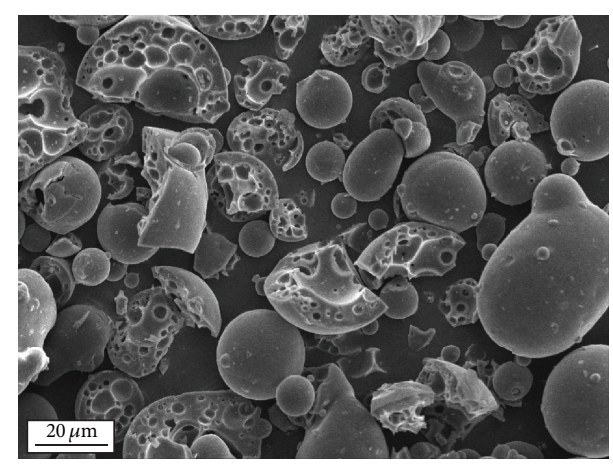

(b)

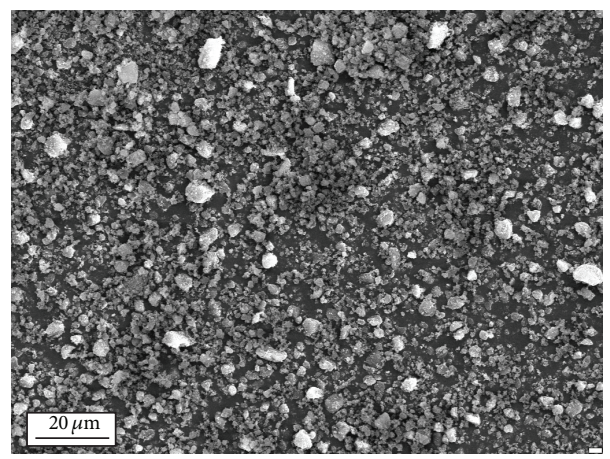

(d)

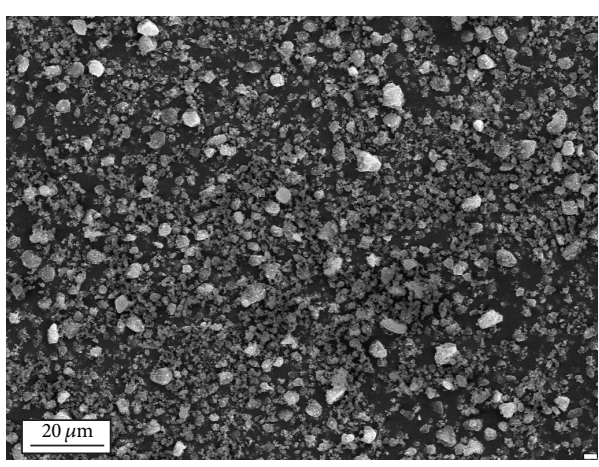

(e)

Figure 2: SEM images of silica Syloid 244 (a), kraft lignin (b), and silica-lignin hybrid fillers with weight ratio equal to 1:1 (c), $2: 1$ (d), and $5: 1(\mathrm{e})$. 


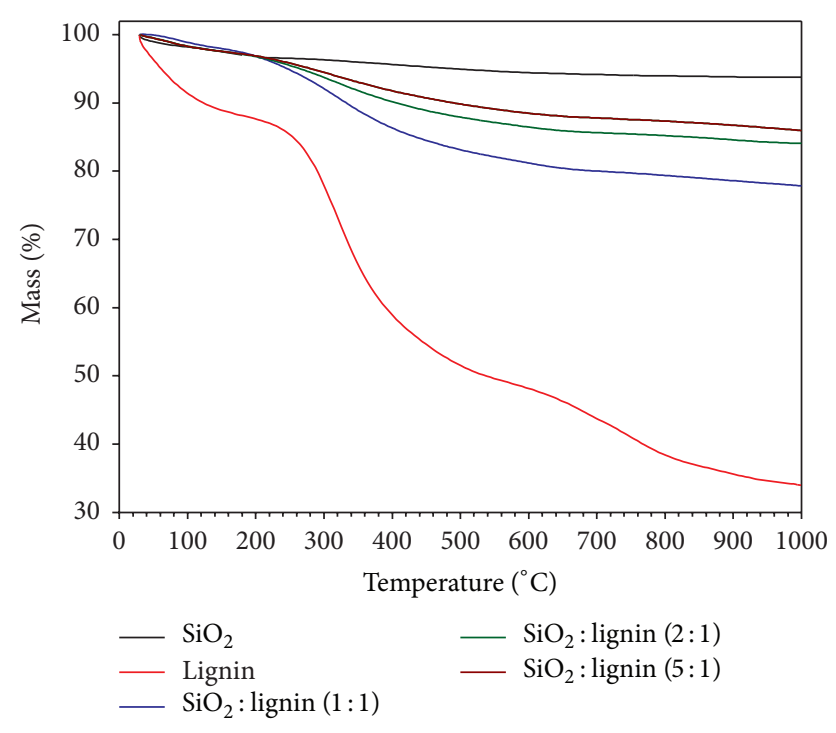

FIGURE 3: Thermal degradation curves versus temperature for pure silica and lignin as well as for silica-lignin hybrid fillers.

individual steps of the mass loss at particular temperatures for lignin are presented in Table 3.

Figure 3 also presents the TGA curves obtained for the prepared silica-lignin hybrid fillers. The final hybrid materials show rather greater thermal stability than is exhibited by pure lignin. The thermal analysis showed that the higher the content of lignin in the product, the poorer its thermal stability. Moreover, with an increase in lignin content, the TGA curves become more similar to those of pure lignin, and the mass loss is larger. The promising TGA results obtained at this stage of the study suggest that the silica-lignin products may be used as a new generation of polymer dual fillers.

\subsection{Thermogravimetry Analysis of Composites. Figure 4} shows the basic thermal degradation curves, measured in nitrogen, as a function of increasing temperature, obtained for extrudates extruded at $100 \mathrm{rpm}$ screw speed. We can see in this figure that the mass loss for pure PP is much more rapid than that for the composite with lignin at temperatures up to $430^{\circ} \mathrm{C}$. Next, the curve for PP shows visible thermal degradation below $470^{\circ} \mathrm{C}$ without char formation. On the other hand, for the composite with lignin, we observe a curve with char yield formation. This feature is connected with the aromatic chemical structure of lignin, which may give a very high char yield, which is still high even at $700^{\circ} \mathrm{C}$ [35]. Other curves obtained from the blends with hybrid fillers with silica-lignin ratios of $1: 1$ and $5: 1$ possess higher thermal stability, up to $450^{\circ} \mathrm{C}$, than the other tested materials. This may be connected with the relatively high surface area of the silica filler. The presence of silica in polymer matrices leads to the formation of an interlayer zone at the filler surface and thus the immobilization of polymeric chains on the filler surface. This feature increases the thermal stability of the polymeric phase. Surprisingly, the sample with a silica-lignin ratio of $2: 1$ in the hybrid structure exhibits markedly lower thermal stability.
TABLE 3: The individual steps of the mass loss in relation to particular temperatures for lignin.

\begin{tabular}{cccc}
\hline Stage & $\begin{array}{c}\text { Mass loss } \\
(\%)\end{array}$ & $\begin{array}{c}\text { Temperature } \\
\left({ }^{\circ} \mathrm{C}\right)\end{array}$ & Reason/cause \\
\hline 1 & 12 & $20-150$ & $\begin{array}{c}\text { Desorption of physically } \\
\text { bound water with the } \\
\text { product surface }\end{array}$ \\
3 & 40 & $150-550$ & $\begin{array}{c}\text { Thermal decomposition } \\
\text { of lignin macromolecule } \\
\text { Fragmentation }\end{array}$ \\
& 13 & $550-1000$ & $\begin{array}{c}\text { combined with the final } \\
\text { thermal decomposition } \\
\text { of the compound }\end{array}$ \\
\hline
\end{tabular}

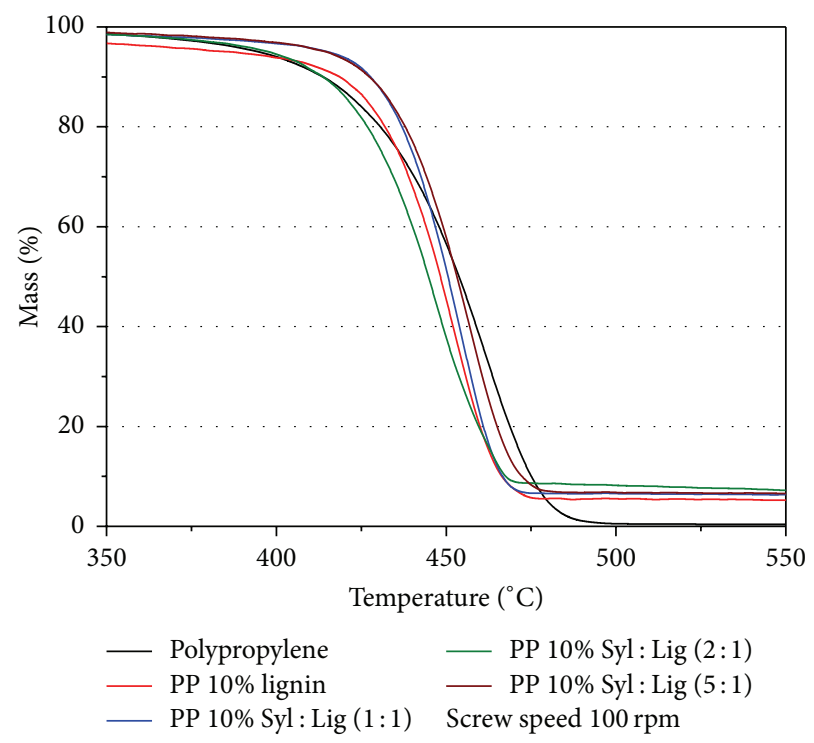

FIgure 4: Thermal degradation curves versus temperature for pure $\mathrm{PP}$ and its blends with lignin and hybrid fillers, after extrusion with $100 \mathrm{rpm}$ of screw speed.

In addition, Figure 5 shows curves obtained for the same materials but processed under higher shear forces, with a screw speed of $400 \mathrm{rpm}$. It can be clearly noted that the thermal decomposition $T_{D}$, the temperature at which half of the initial mass of the sample is lost, is especially low for polypropylene filled with lignin. This composite has a degradation temperature approximately $20^{\circ} \mathrm{C}$ lower than that of the other tested materials, previously treated in the extruder under the same conditions.

Table 4 summarizes the TGA and DTG experimental data, including the thermal degradation temperatures at which $5 \%$ and $50 \%$ of the initial mass are lost $\left(T_{D 5 \%}\right.$ and $\left.T_{D 50 \%}\right)$ and the percentage of char produced at $700^{\circ} \mathrm{C}$ for all examined samples. Also, the temperature for the maximum rate of weight loss, $T_{\mathrm{MR}}$, is given in Table 4 . We can see that pure PP degrades completely without any char formation, with the residual of the original sample mass being only $0.3 \%$.

The thermal behavior of the composite with lignin is different. The tested samples revealed a significant char residue (4.19wt.\% and $3.17 \mathrm{wt} . \%$ for samples extruded at 
TABLE 4: Comparison of the thermal decomposition temperatures of PP/silica-lignin composites under different extrusion conditions char wt.\% formed during the test.

\begin{tabular}{|c|c|c|c|c|c|}
\hline Sample & Screw speed & $T_{D 5 \%}\left({ }^{\circ} \mathrm{C}\right)$ & $T_{D 50 \%}\left({ }^{\circ} \mathrm{C}\right)$ & $T_{\mathrm{MR}}\left({ }^{\circ} \mathrm{C}\right)$ & Char (wt.\%) \\
\hline $\mathrm{PP}$ & - & 397 & 453 & 445 & 0.30 \\
\hline PP/lignin & \multirow{4}{*}{$100 \mathrm{rpm}$} & 387 & 448 & 454 & 4.19 \\
\hline $\mathrm{PP} / \mathrm{SiO}_{2}$-lignin $(1: 1)$ & & 415 & 450 & 455 & 5.80 \\
\hline $\mathrm{PP} / \mathrm{SiO}_{2}$-lignin $(2: 1)$ & & 398 & 445 & 447 & 7.00 \\
\hline 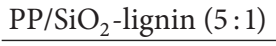 & & 423 & 456 & 460 & 6.17 \\
\hline PP/lignin & \multirow{4}{*}{$400 \mathrm{rpm}$} & 377 & 440 & 446 & 3.17 \\
\hline $\mathrm{PP} / \mathrm{SiO}_{2}$-lignin $(1: 1)$ & & 415 & 453 & 457 & 6.08 \\
\hline $\mathrm{PP} / \mathrm{SiO}_{2}$-lignin $(2: 1)$ & & 420 & 452 & 454 & 3.61 \\
\hline $\mathrm{PP} / \mathrm{SiO}_{2}$-lignin $(5: 1)$ & & 423 & 454 & 456 & 3.77 \\
\hline
\end{tabular}

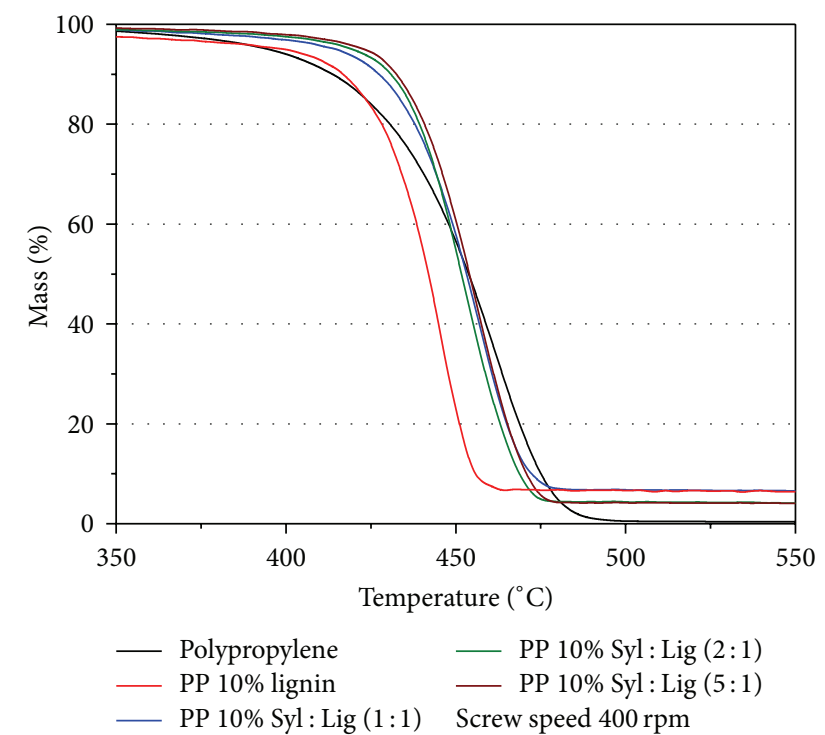

FIGURE 5: Thermal degradation curves versus temperature for pure $\mathrm{PP}$ and its blends with lignin and hybrid fillers, after extrusion with $400 \mathrm{rpm}$ of screw speed.

$100 \mathrm{rpm}$ and $400 \mathrm{rpm}$ resp.). Lignin has a thermal degradation temperature about $50^{\circ} \mathrm{C}$ less than that of $\mathrm{PP}$, and it produces a very high quantity of char in an inert atmosphere (see Figure 3). This property was also confirmed by Canetti et al. [36]. When polypropylene/lignin composites start to degrade, the charring aromatic radicals from lignin [37] reduce the $\mathrm{PP}$ degradation rate $\left(T_{\mathrm{MR}}\right)$ and produce char as a protective coat (see Figure 6).

Based on these results, it is clear in our opinion that thermal decomposition of polypropylene with kraft lignin is greatly influenced by the shear rate during extrusion. Without silica protection, the heat (additionally generated by intermolecular friction) and shear forces cause some negative effects on the lignin structure and lead to a very low thermal decomposition temperature $\left(T_{D 50 \%}\right)$. This effect is also seen in the decrease in the temperature of maximum rate of weight loss $\left(T_{\mathrm{MR}}\right)$ for $\mathrm{PP} /$ lignin composites. Based on this finding, treating thermoplastic composites with lignin under a very high screw speed is not recommended. For the remainder

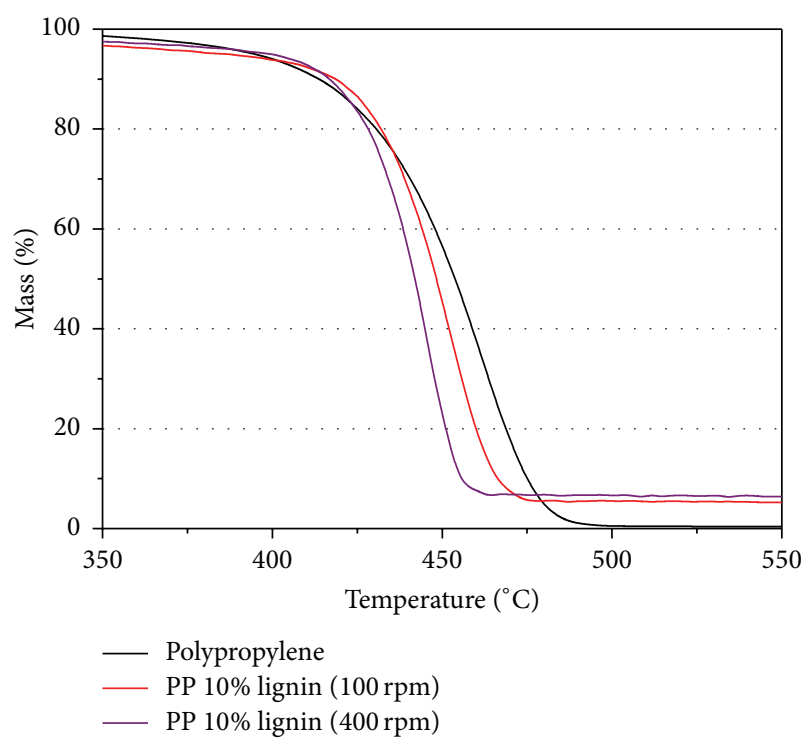

FIGURE 6: Thermal degradation curves versus temperature for pure PP and its blends with lignin after extrusion with 100 and $400 \mathrm{rpm}$ of screw speed.

of the tested samples, in general, the char yield increases with an increase in the quantity of inorganic additive. Some deviations were observed for the sample of PP/silica-lignin $(1: 1)$ at $400 \mathrm{rpm}$ screw speed and may have their source in the degree of homogeneity of the composite samples. Moreover, the addition of an inorganic component such as silica generally increased the initial thermal decomposition temperature $\left(T_{D 5 \%}\right)$ by about $15-20^{\circ} \mathrm{C}$, with a significant char yield (see Figure 7).

3.3. Mechanical Parameters and Melt Flow Rate Index. Melt mass flow rate is presented in Figure 8. For composite $\mathrm{PP} /$ lignin, for every extrusion step, a gradual increase in the MFR index is observed. This is a result of the thermomechanical degradation of PP macromolecules and the lignin filler. For composites with the hybrid filler, an unexpected increase in flow rate is observed in samples processed at $100 \mathrm{rpm}$ and $400 \mathrm{rpm}$ screw speed. This is probably the result of poor homogeneity in the composites. For the composites with the 


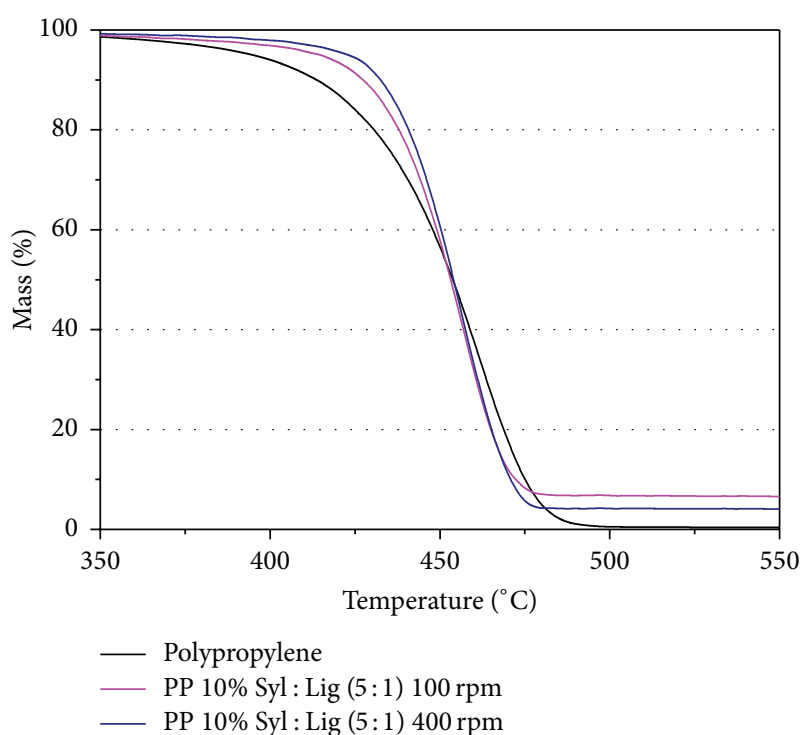

FIgURE 7: Thermal degradation curves versus temperature for pure PP and its blends with hybrid filler containing $20 \%$ of lignin, made with 100 and $400 \mathrm{rpm}$ of screw speed respectively.

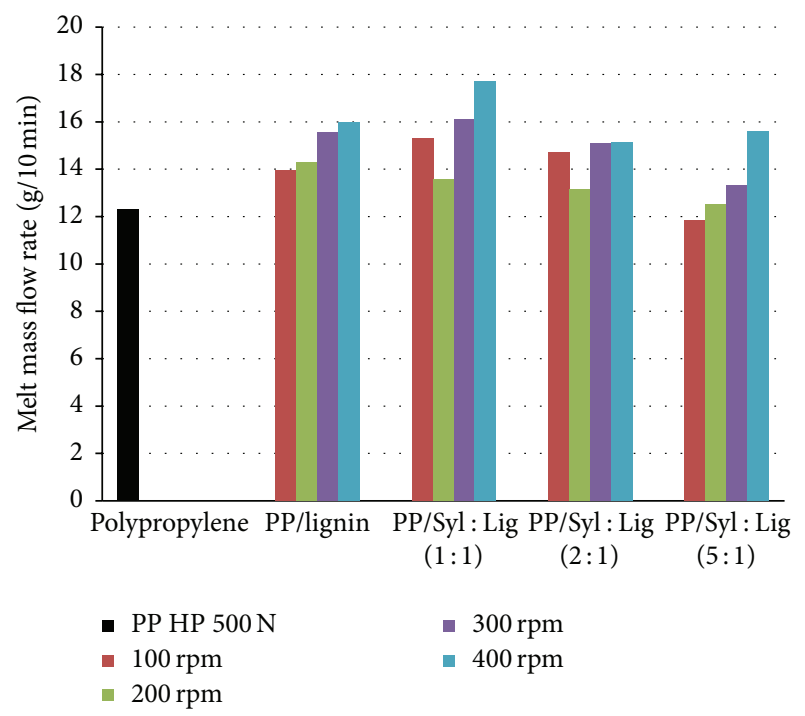

FIGURE 8: Mass melt flow rate for all tested materials versus applied screw speed.

highest amount of silica, the thermomechanical degradation processes during extrusion are hidden or limited by the interaction between the large BET surface area $\left(244 \mathrm{~m}^{2} / \mathrm{g}\right)$ and polymer molecules. These interactions occur due to the formation of an oriented layer on the filler particle and the consequent reduction in Brownian motion of the molecules.

The variations in tensile strength, Young's modulus, and elongation at break as a function of lignin and hybrid filler content are shown in Figures 9-11.

The tensile strength is observed to increase slightly with the addition of filler. As a rigid filler, having a high BET surface area, the silica is also a reinforcing agent. Surprisingly,

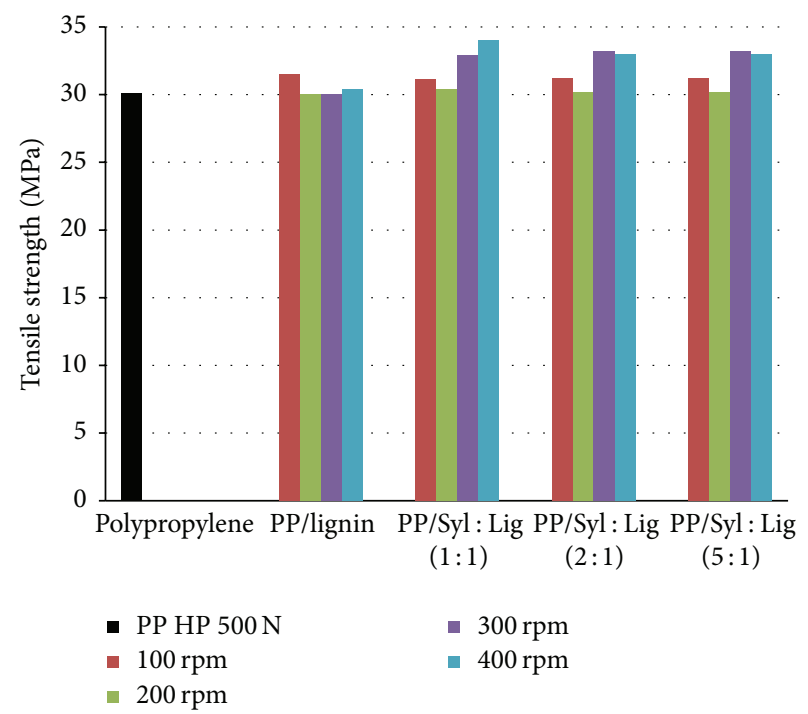

FIgURE 9: Tensile strength obtained during static uniaxial deformation versus applied screw speed.

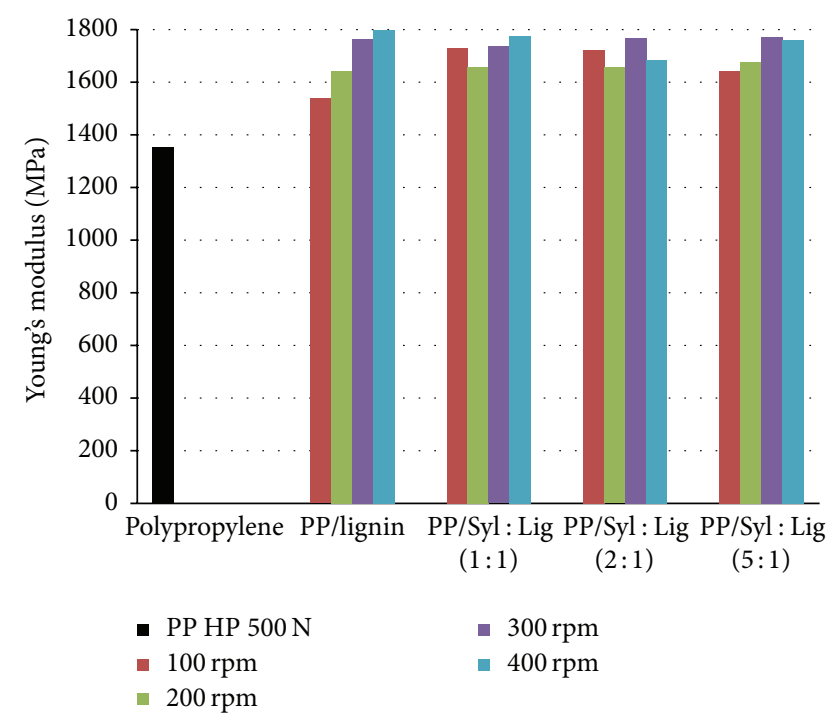

FIGURE 10: Young modulus obtained during static uniaxial deformation versus applied screw speed.

application of the highest screw speed results in visible positive changes in both tensile strength and stiffness of the composites. The explanation of these phenomena may be connected with the better dispersion of the filler achieved during extrusion at the highest screw speed. Fine filler particles embedded in the polymer may create a higher volume of the matrix at the intermediate layer created by the filler and may also act as a nucleating agent (especially in the case of hybrid fillers containing silica).

By contrast, there was a significant reduction in the strain at break. This may be due to the introduction of a rigid filler with particles on the macroscale. These particles are unable to deform, and under high elongation some voids appear at the filler-polymer interphase. This may lead to crack 


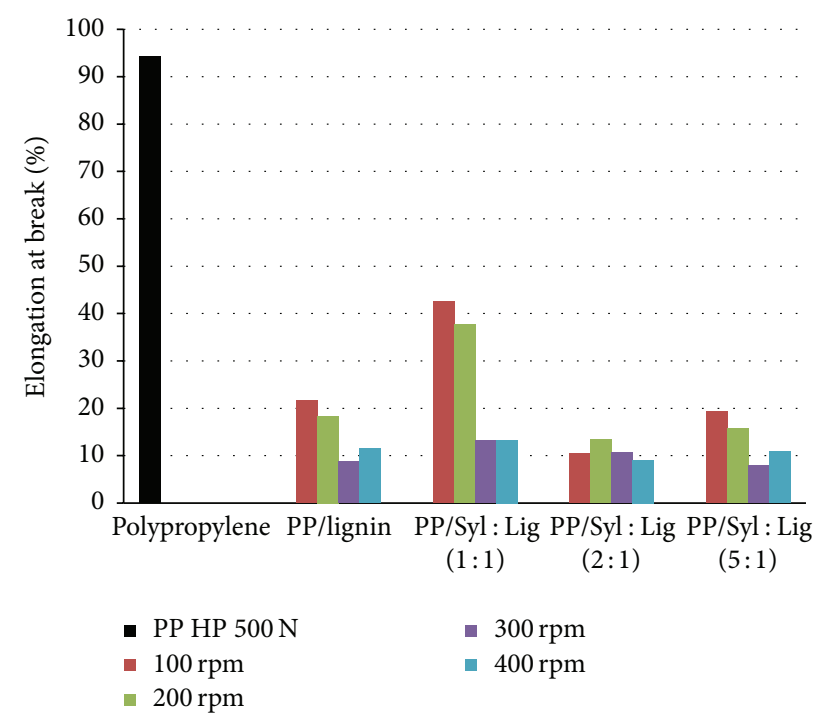

FIGURE 11: Elongation at break obtained during static uniaxial deformation versus applied screw speed.

formation and reduction in matrix plasticity. Moreover, the rapid decrease in elongation at break appeared at a rather high loading level of particular fillers. Very similar results were observed by $\mathrm{Hu}$ et al. [38] in polyethylene filled with $40 \%$ kraft lignin. Those authors tried to overcome this unfavorable effect by the addition of compatibilizers, mainly EVA, MAPE, and SEBS. The addition of EVA to the composite formulation enabled an increase in the elongation at break by $67 \%$, and this was the best achieved result. In our work, we achieved an increase in the elasticity by more than $100 \%$ for composites with hybrid filler (kraft lignin combined with silica in a ratio of $50: 50 \mathrm{wt} . \%$ ) processed at $100 \mathrm{rpm}$ and $200 \mathrm{rpm}$ screw speed.

For future applications, we also believe that this unfavorable property can be limited by the use of block or random PPE copolymer as a polymer matrix. Usually, the presence of polyethylene macromolecules gives more flexibility and much higher plasticity to composite systems.

\section{Conclusions}

Advanced silica-lignin hybrid fillers have been obtained using as precursors Syloid 244 silica and kraft lignin. The tested hybrid components, as well as $\mathrm{SiO}_{2}$-lignin dual fillers, have been thoroughly characterized by the determination of their dispersive-morphological properties and thermal stability. With the increasing content of lignin in the hybrid filler, the number of larger particles increases. This tendency is evident for the hybrid fillers based on Syloid 244 silica. The final hybrids show rather greater thermal stability than what is exhibited by pure lignin. The thermal analysis showed that the higher the content of lignin in the product, the poorer its thermal stability.

In addition, the novel hybrid so-called "dual phase fillers" were tested as a precursor in the retention of thermal degradation of polymer composites with lignin in polypropylene.
The presence of silica in the blend is able to bring about a significant shift in the initial degradation temperature, which corresponds to $5 \%$ weight loss of the polypropylene/lignin systems. Thus, the processing of green polymer composites via extrusion with relatively high screw speed could be protected by a fraction of active silica with a high BET surface area. As we demonstrated, the new type of dual phase silicalignin fillers has a positive impact on the main mechanical parameters. We noted a very positive effect of combining silica with kraft lignin, in the form of a sharp increase in elongation at break compared with composites filled with lignin. This may be connected with better dispersion of dual phase filler particles, together with thermal ageing protection of the lignin phase.

\section{Conflict of Interests}

The authors declare that there is no conflict of interests regarding the publication of this paper.

\section{Acknowledgment}

The study was financed within the National Science Centre Poland funds according to decision no. DEC2013/09/B/ST8/00159.

\section{References}

[1] Y. Qu, Y. Tian, B. Zou et al., "A novel mesoporous lignin/silica hybrid from rice husk produced by a sol-gel method," Bioresource Technology, vol. 101, no. 21, pp. 8402-8405, 2010.

[2] Ł. Klapiszewski, M. Nowacka, G. Milczarek, and T. Jesionowski, "Physicochemical and electrokinetic properties of silica/lignin biocomposites," Carbohydrate Polymers, vol. 94, no. 1, pp. 345355,2013

[3] T. Jesionowski, Ł. Klapiszewski, and G. Milczarek, "Kraft lignin and silica as precursors of advanced composite materials and electroactive blends," Journal of Materials Science, vol. 49, no. 3, pp. 1376-1385, 2014.

[4] Ł. Klapiszewski, J. Zdarta, T. Szatkowski et al., "Silica/lignosulfonate hybrid materials: preparation and characterization," Central European Journal of Chemistry, vol. 12, no. 6, pp. 719-735, 2014.

[5] G. Milczarek, M. Motylenko, A. Modrzejewska-Sikorska et al., "Deposition of silver nanoparticles on organically-modified silica in the presence of lignosulfonate," RSC Advances, vol. 4, no. 94, pp. 52476-52484, 2014.

[6] J. F. Kadla and S. Kubo, "Lignin-based polymer blends: analysis of intermolecular interactions in lignin-synthetic polymer blends," Composites Part A: Applied Science and Manufacturing, vol. 35, no. 3, pp. 395-400, 2004.

[7] M. Canetti and F. Bertini, "Supermolecular structure and thermal properties of poly(ethylene terephthalate)/lignin composites," Composites Science and Technology, vol. 67, no. 15-16, pp. 3151-3157, 2007.

[8] F. Chen, H. Dai, X. Dong, J. Yang, and M. Zhong, "Physical properties of lignin-based polypropylene blends," Polymer Composites, vol. 32, no. 7, pp. 1019-1025, 2011. 
[9] S. Borysiak, "Fundamental studies on lignocellulose/polypropylene composites: effects of wood treatment on the transcrystalline morphology and mechanical properties," Journal of Applied Polymer Science, vol. 127, no. 2, pp. 1309-1322, 2013.

[10] S. Borysiak, "The thermo-oxidative stability and flammability of wood/polypropylene composites," Journal of Thermal Analysis and Calorimetry, vol. 119, no. 3, pp. 1955-1962, 2015.

[11] O. Gordobil, I. Egüés, R. Llano-Ponte, and J. Labidi, "Physicochemical properties of PLA lignin blends," Polymer Degradation and Stability, vol. 108, pp. 330-338, 2014.

[12] I. Spiridon, K. Leluk, A. M. Resmerita, and R. N. Darie, "Evaluation of PLA-lignin bioplastics properties before and after accelerated weathering," Composites Part B: Engineering, vol. 69, no. 1, pp. 342-349, 2015.

[13] G. Faludi, J. Hári, K. Renner, J. Móczó, and B. Pukánszky, “Fiber association and network formation in PLA/lignocellulosic fiber composites," Composites Science and Technology, vol. 77, no. 1, pp. 67-73, 2013.

[14] G. Faludi, G. Dora, K. Renner, J. Móczó, and B. Pukánszky, "Biocomposite from polylactic acid and lignocellulosic fibers: structure-property correlations," Carbohydrate Polymers, vol. 92, no. 2, pp. 1767-1775, 2013.

[15] C. Gozdecki, A. Wilczyński, M. Kociszewski, J. Tomaszewska, and S. Zajchowski, "Mechanical properties of woodpolypropylene composites with industrial wood particles of different sizes," Wood and Fiber Science, vol. 44, no. 1, pp. $14-21,2012$.

[16] J. Tomaszewska, T. Sterzyński, and S. Zajchowski, “Thermal and structural effects of poly(vinyl chloride)/(wood flour) compound gelation in the Brabender mixer," Journal of Vinyl and Additive Technology, vol. 17, no. 4, pp. 239-244, 2011.

[17] M. Brebu and C. Vasile, "Thermal degradation of lignin-a review," Cellulose Chemistry and Technology, vol. 44, no. 9, pp. 353-363, 2010.

[18] C. Heitner, D. R. Dimmel, and J. A. Schmidt, Eds., Lignin and Lignans. Advanced in Chemistry, CRC Press, Boca Raton, Fla, USA, 2010.

[19] M. Poletto, A. J. Zattera, M. M. C. Forte, and R. M. C. Santana, "Thermal decomposition of wood: influence of wood components and cellulose crystallite size," Bioresource Technology, vol. 109, no. 1, pp. 148-153, 2012.

[20] M. Kijima, T. Hirukawa, F. Hanawa, and T. Hata, "Thermal conversion of alkaline lignin and its structured derivatives to porous carbonized materials," Bioresource Technology, vol. 102, no. 10, pp. 6279-6285, 2011.

[21] M. Brebu, G. Cazacu, and O. Chirila, "Pyrolysis of lignina potential method for obtaining chemicals and/or fuels," Cellulose Chemistry and Technology, vol. 45, no. 1-2, pp. 43-50, 2011.

[22] A. P. Lemes, M. A. Soto-Oviedo, W. R. Waldman, L. H. Innocentini-Mei, and N. Durán, "Effect of lignosulfonate on the thermal and morphological behavior of poly(3hydroxybutyrate-co-3-hydroxyvalerate)," Journal of Polymers and the Environment, vol. 18, no. 3, pp. 250-259, 2010.

[23] D. Stawski, S. Rabiej, L. Herczyńska, and Z. Draczyński, “Thermogravimetric analysis of chitins of different origin," Journal of Thermal Analysis and Calorimetry, vol. 93, no. 2, pp. 489-494, 2008.

[24] S. Deguchi, K. Tsujii, and K. Horikoshi, "In situ microscopic observation of chitin and fungal cells with chitinous cell walls in hydrothermal conditions," Scientific Reports, vol. 5, no. 1, article 11907, 8 pages, 2015.
[25] Y. S. Nam, W. H. Park, D. Ihm, and S. M. Hudson, "Effect of the degree of deacetylation on the thermal decomposition of chitin and chitosan nanofibers," Carbohydrate Polymers, vol. 80, no. 1, pp. 291-295, 2010.

[26] M. Wysokowski, I. Petrenko, A. Stelling, D. Stawski, T. Jesionowski, and H. Ehrlich, "Poriferan chitin as a versatile template for extreme biomimetics," Polymers, vol. 7, no. 2, pp. 235-265, 2015.

[27] E. Parparita, C. N. Cheaburu, and C. Vasile, "Morphological, thermal and rheological characterization of polyvinyl alcohol/chitosan blends," Cellulose Chemistry and Technology, vol. 46, no. 9-10, pp. 571-581, 2012.

[28] L. Chen, C.-Y. Tang, N.-Y. Ning, C.-Y. Wang, Q. Fu, and Q. Zhang, "Preparation and properties of chitosan/lignin composite films," Chinese Journal of Polymer Science, vol. 27, no. 5, pp. 739-746, 2009.

[29] V. Georgieva, D. Zvezdova, and L. Vlaev, "Non-isothermal kinetics of thermal degradation of chitosan," Chemistry Central Journal, vol. 6, no. 81, pp. 1-10, 2012.

[30] D. Paukszta and S. Borysiak, "The influence of processing and the polymorphism of lignocellulosic fillers on the structure and properties of composite materials-a review," Materials, vol. 6, no. 7, pp. 2747-2767, 2013.

[31] M. Gao and Q.-J. Dai, "Studies on thermal degradation of cellulosic fibers treated with flame retardants," The Chinese Journal of Process Engineering, vol. 6, no. 2, pp. 242-246, 2006.

[32] F.-Y. Huang, "Thermal properties and thermal degradation of cellulose tri-stearate (CTs)," Polymers, vol. 4, no. 2, pp. 10121024, 2012.

[33] K. Bula, Ł. Klapiszewski, and T. Jesionowski, "A novel functional silica/lignin hybrid material as a potential bio-based polypropylene filler," Polymer Composites, vol. 36, no. 5, pp. 913-922, 2015.

[34] Ł. Klapiszewski, T. Rzemieniecki, M. Krawczyk et al., "Kraft lignin/silica-AgNPs as a functional material with antibacterial activity," Colloids and Surfaces B: Biointerfaces, vol. 134, pp. 220228, 2015.

[35] A. De Chirico, M. Armanini, P. Chini, G. Cioccolo, F. Provasoli, and G. Audisio, "Flame retardants for polypropylene based on lignin," Polymer Degradation and Stability, vol. 79, no. 1, pp. 139145, 2003.

[36] M. Canetti, F. Bertini, A. De Chirico, and G. Audisio, "Thermal degradation behaviour of isotactic polypropylene blended with lignin," Polymer Degradation and Stability, vol. 91, no. 3, pp. 494-498, 2006.

[37] J. Li, B. Li, X. Zhang, and R. Su, "The study of flame retardants on thermal degradation and charring process of manchurian ash lignin in the condensed phase," Polymer Degradation and Stability, vol. 72, no. 3, pp. 493-498, 2001.

[38] L. Hu, T. Stevanovic, and D. Rodrigue, "Compatibilization of kraft lignin-polyethylene composites using unreactive compatibilizers," Journal of Applied Polymer Science, vol. 131, no. 21, Article ID 41040, 2014. 

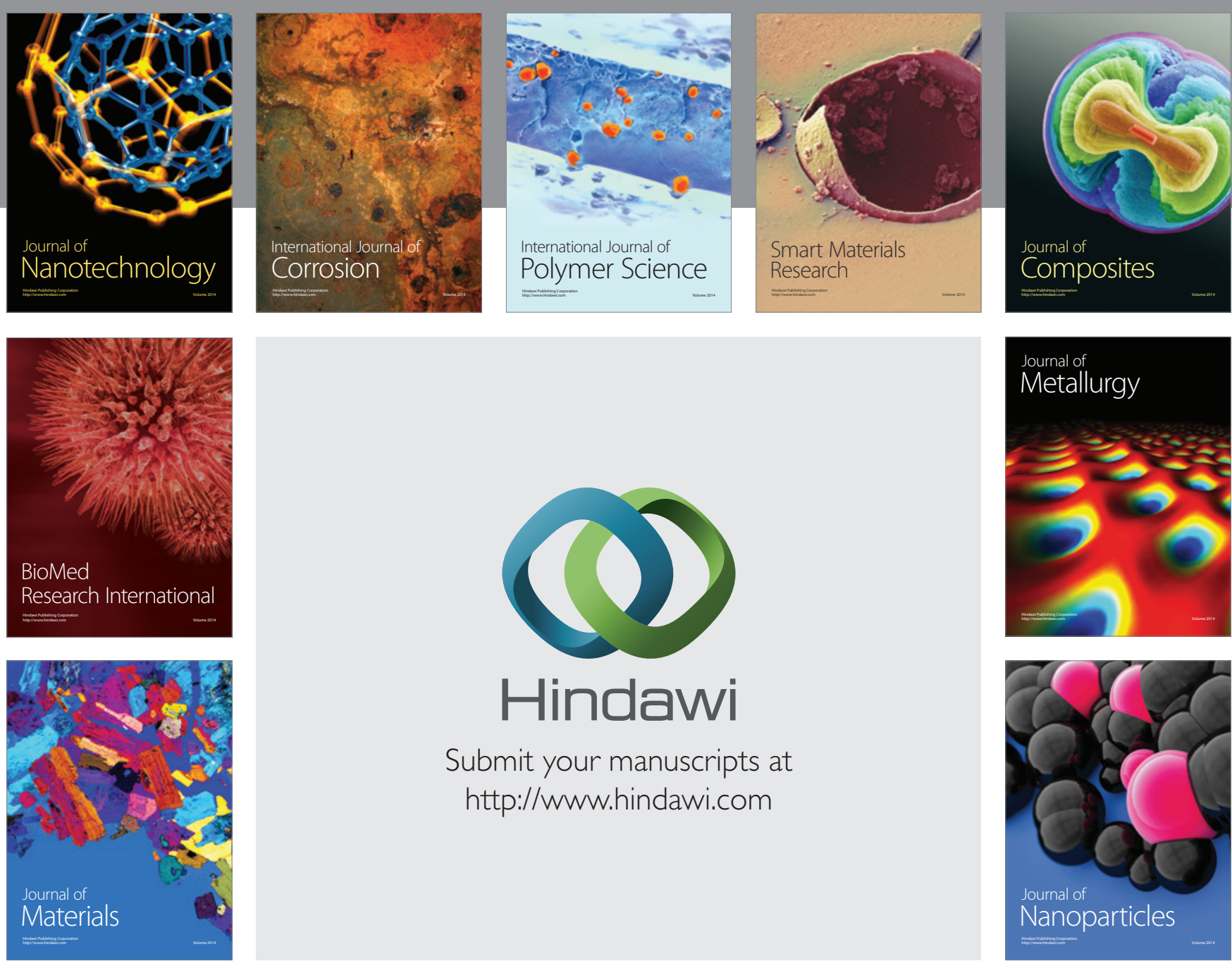

\section{Hindawi}

Submit your manuscripts at

http://www.hindawi.com

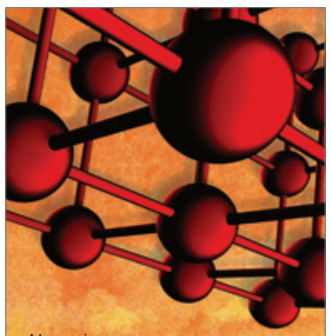

Materials Science and Engineering
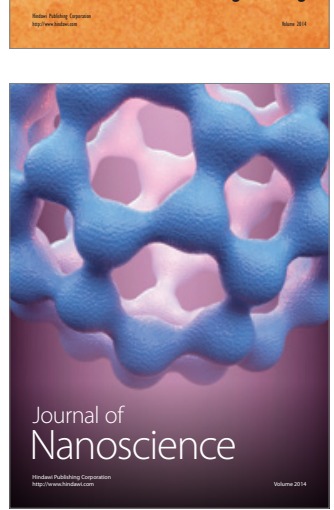
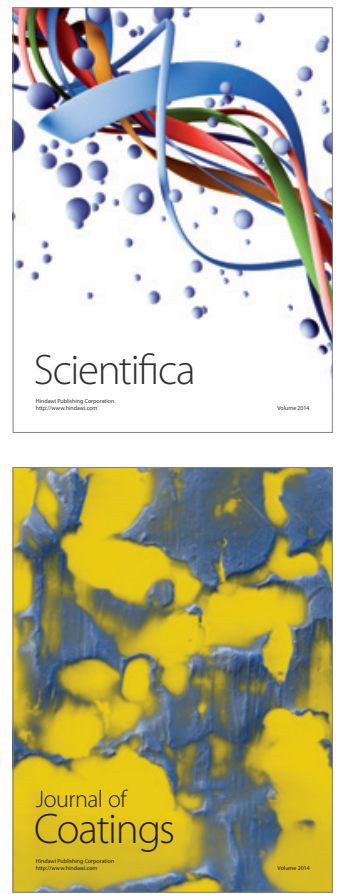
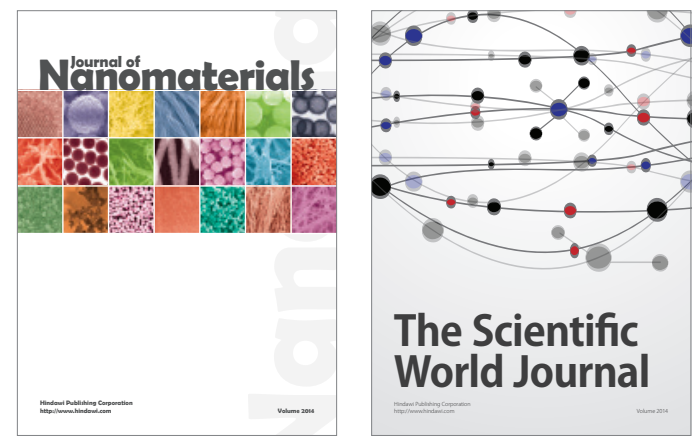

The Scientific World Journal
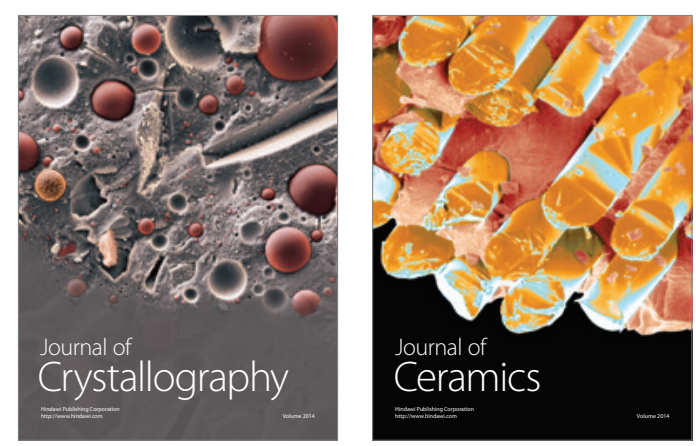
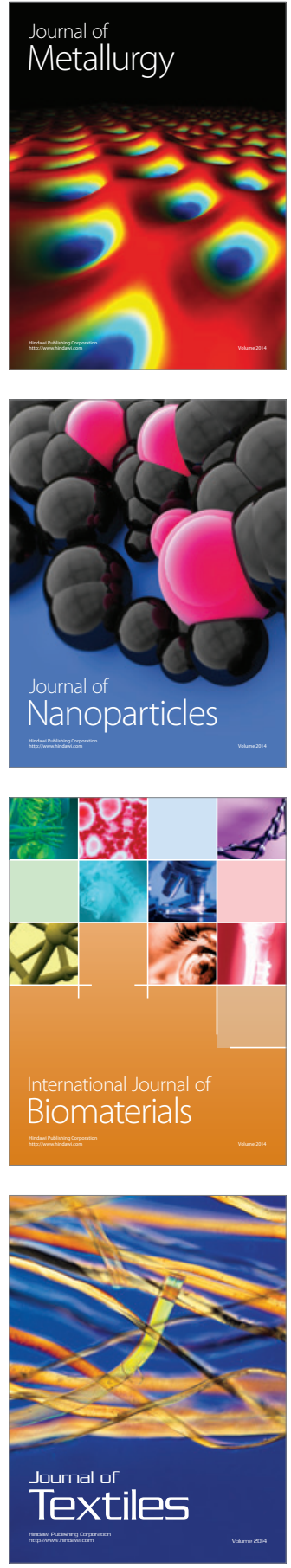